\title{
Interrelation of Information and Knowledge in the Economy of the Post-Industrial Society
}

\author{
A.M. Mikhailov ${ }^{1}$ and A.A. Kopylova ${ }^{1, *}$ \\ *Corresponding author: 2427994@mail.ru \\ ${ }^{1}$ Samara State University of Economics, Samara, Russia
}

\begin{abstract}
Relevance of the study is to consider that in the post-industrial society the role of information and knowledge is so increased that they begin to occupy a decisive place in the production development. The purpose of the work is investigated interrelation of information and knowledge in the process of intellectual activity, which is a component of the production activity of the post-industrial production. The study task is to examine the role of information and knowledge in the formation of the new economy replacing the industrial one. In this paper used abstract-logical method historical method systemic and dialectical methods of analysis and synthesis. As a result of the research were justified "information" and "knowledge" as independent and interrelated categories; identifying peculiarities of knowledge that distinguish it from traditional production factors; studying intellectual activity as a component of the production activity.
\end{abstract}

Keywords: information; knowledge; post-industrial society; production factors; intellectual activity.

\section{Introduction}

Information and knowledge have always taken on enormous importance in the development of a human society. The production process was impossible without their use in either traditional or industrial society. However, their role is so increased in the post-industrial society [1] that they begin to occupy a decisive place in the production development. Currently, when traditional resources and sources are close to depletion, the economic growth is increasingly achieved by means of using information sources and resources.

The authors of the post-industrial society theory consider the change of "machine technologies" of the industrial production with "intellectual technologies" of the post-industrial society to be the most important consequence of the contemporary scientific and technological revolution [2]. As a result, fundamentally new approaches to the study of whole technical, economic and social problems appear [3]. At present day, in developed countries, it is less than $30 \%$ workers who directly influence the material subject of labor, but no longer $90 \%$ of them as it was in the industrial economy [4]. The share of industries directly related to the production and use of knowledge in the gross national product of developed countries grows at an ever increasing rate. It was about one third in the USA in the middle of the $\mathrm{XX}^{\text {th }}$ century, and it was already three fifths by the end of the century [5].

\section{Problem Statement}

The study task is to examine the role of information and knowledge in the formation of the new economy replacing the industrial one. The possibility of transition to the new economy lies in a person's ability to assimilate, analyze and convert information into knowledge. Such concepts as knowledge economy [6], knowledge based economy [7] and information economy [8] are used in economic literature to designate the new economy. When describing it, such concepts as innovative economy [9] and digital economy [10] are also widely used. The new economy has replaced the industrial one and it can be defined, in our opinion, as the post-industrial economy. The transition from the industrial era to the post-industrial one is associated with informatization. As a result, economy of the post-industrial society is characterized, firstly, as informational economy. Secondly, not only information, but knowledge, i.e. data set assimilated by a human and not existing outside his/her consciousness, is important for the production process.

\section{Research Questions}

The study of the interrelation of information and knowledge in the economy of the postindustrial society requires the study of the following key issues:

- justifying information and knowledge as independent and interrelated categories;

- identifying peculiarities of knowledge that distinguish it from traditional production factors;

- studying intellectual activity as a component of the production activity. 


\section{Purpose of the Study}

New types of productive resources require research to determine methods for the effective functioning of the postindustrial economy. The purpose of the work is to investigate the interrelation of information and knowledge in the process of intellectual activity, which is a component of the production activity of the post-industrial production.

\section{Research Methods}

Theoretical conceptual approaches to studying the role of information and knowledge in the post-industrial society are reflected in the researches of such scientists as D. Bell [1], F. Fukuyama [3], R. Ayres [5], A. De Geus [11], P. Drucker [12], V. Inozemtsev [13], and others. This paper presents the categories of information and knowledge based on application of the abstract-logical method and the relationship between them; the historical method is used to study the role of information and knowledge at various stages of the society development: traditional, industrial and postindustrial; using the systemic and dialectical methods of analysis and synthesis, the properties of knowledge as a fifth independent factor of the post-industrial production and the role of intellectual activity in the structure of the production activity are revealed.

\section{Findings}

Information and knowledge always contributed to more efficient use of production factors. They are important for all owners of production factors. Every owner of production factors should possess information and knowledge. The effective use of production factors is impossible without them. An owner of production factors having mastered the information and knowledge applies them during his/her economic activity. This contributes to a more effective use of production factors. A landowner can lease a land on more favorable terms and get more income. A capitalist can more profitably invest his/her funds. An employee can more efficiently and more productively spend his/her labor force. An entrepreneur can more effectively connect production factors and use them more effectively based on knowledge.

Information and knowledge are resources as they can exist without connecting with other resources. Resources are independent of each other. They become production factors by connecting with other resources. Production factors exist only in interaction with each other.

Knowledge, as a resource, is a person's ability to intellectual activity, similar to labor that is the ability to work. They are not alienable from their carrier - a human [14]. One can grant his/her knowledge for temporary use while remaining its owner [15].

The "information" and "knowledge" categories should not be identified. They differ primarily in that information is an objective set of facts. But knowledge has subjective nature, since it is inseparable from human consciousness. Moreover, namely knowledge, but not information, becomes a production factor. Knowledge as a factor of production is information that have been processed, assimilated and, most importantly, used in production. A book is a set of information; a read book is knowledge as a resource; and if the result of reading is an action in the production process, in this case we already talk about knowledge as a production factor.

Knowledge as a production factor in the new economy has a number of peculiarities that distinguish it from traditional production factors:

- knowledge is inexhaustible; the same knowledge can be used an infinite number of times without any harm to itself;

- there can never be a surplus of knowledge, as it often may be with other resources, in particular with a labor force;

- the development of knowledge is aimed, in principle, to infinity, i.e. knowledge does not contain a limit to its development in itself;

- the same knowledge can be used by an infinite number of people at the same time.

Each personal production factor is associated with a specific type of production activity:

- labor is a process of conscious purposeful human activity on the transformation of the substance of nature, the result of which is a material product (a labor activity);

- industrial entrepreneurship is an activity of combining and economic utilization of production factors (an entrepreneurial activity);

- knowledge in the production process is associated with intellectual activity on the application, transformation and multiplication of knowledge, the result of which is an intellectual component of the product.

In the traditional society, a production activity was reduced to a labor activity. In the industrial society, the division of labor led to separation an entrepreneurial activity as an independent one, and entrepreneurship became considered to be an independent fourth production factor [16]. And in the post-industrial society, an intellectual activity is separated as part of the production activity, and knowledge becomes an independent fifth production factor.

At the same time, knowledge progressively becomes a leading factor, as it changes the social development at an ever-increasing pace [12]. In the traditional society, a land was a leading and relatively scarce production factor. In the industrial society, the role of a land as a production factor is reduced compared to capital and then to entrepreneurship. In the post-industrial society, "knowledge, being a rare production factor, replaces capital" [11]. The capital invested in material resources does not disappear, but it is inferior by value to the human capital [17]. The role of a labor factor is 
relatively reduced [18]. The share of employees engaged in labor operations in the economies of developed countries is decreased. It decreased by $2 \%$ in the United States and by $3 \%$ in Japan over the past twenty five years [19].

At the same time, reducing the role of traditional production factors does not mean a decrease in significance of the production of material values in modern society. Just as the role of the land factor is preserved in the industrial society, so material and labor resources are necessary in the new economy. Traditional production factors remain a material basis for the development of new social and economic processes of the post-industrial society. With this regard, there is such representative data according to which " $95 \%$ of the value added is not produced independently of $5 \%$ that accounts for the extraction industry, but based on them; thus, the impression of the relative insignificance of the entire extraction industry does not reflect the actual situation" [20].

Intellectual activity is associated with mankind development and a human's aiming for self-actualization [21]. Such features may be inherent to both labor and business activities. At the same time, the results of intellectual activity depend not only and not so much on the involvement of information and knowledge into economic circulation, but on the possibilities of their application. And it depends on a person's intellectual level, his/her abilities, the nature of his/her perception of the world, his/her attitude to himself/herself, and the development of his/her personality. As a result, intellectual activity is associated with the needs of improving the personality of a human, his/her aiming for increasing knowledge (and directly in the process of the production activity). People have always engaged in intellectual activity, but it becomes an essential component of the production development in the post-industrial society [22].

And in our opinion, the problem here is not only in change in the motivations of a human's production activity, as V.L. Inozemtsev believes [13]. Indeed, to carry out intellectual activity, it is necessary to satisfy material needs, and the economic interests of its subjects are implemented through their income as in the process of labor and business activities [23]. In our opinion, the point is that the implementation of intellectual activity is impossible without the selfdevelopment of an individual. For the reproduction of abilities to master information and knowledge, it is necessary to develop a person as an individual and to satisfy his/her needs for self-actualization to use them [24]. In an industrial society, the production progress determined the human development, but in the post-industrial society, the production development depends on the human progress.

\section{Conclusion}

Information and knowledge brought production to a new level. Information affects the human conscience. Knowledge creates technology of interaction of production factors that are able to transform a person himself/herself. Knowledge changes a person, his/her conscience, and as a result, the interaction of production factors is transformed [25]. Knowledge becomes an independent personal production factor as it changes a person himself/herself, a nature of his/her activity [26] and transform the process of interaction of production factors.

The intellectual activity, to a decisive extent, depends on a person's internal needs, but the labor activity is determined, first of all, by economic necessity. At the same time, just as in the process of working activity, there can be satisfaction from performing the work itself, so the activity of mastering and applying knowledge is associated with economic necessity.

The ability to process and use information, apply and produce new knowledge [27] embodied in the intellectual component of the product is the most significant quality of an employee in the technological mode of production in the post-industrial society. An employee's personal growth becomes a production and economic necessity. In the industrial society, the economic result is proportional to the cost of raw materials and other materials. And in the post-industrial society, the costs of materials and labor have a much smaller effect on the economic result. Information becomes a main resource for its achievement, and knowledge is a main factor of its creation.

Therefore, the transition from industrial to post-industrial society is characterized by fundamental changes under the influence of innovative processes of the place and role of information and knowledge in the system of production factors, as well as transformation of their composition and proportion.

\section{References}

1. D. Bell, The third technological revolution and its possible socio-economic consequences. Salford: University of Salford (1988).

2. B. Van Ark, The productivity paradox of the new digital economy. International Productivity Monitor, 3(31), 1-15 (2016).

3. F. Fukuyama, The end of history and the last man. New York N.Y.: The Free Press (1992).

4. M.V. Mikhailov, A.M. Mikhailov, Information and knowledge in the system of the postindustrial production factors. Economic Sciences, 68(7), 49-56 (2010). [in Rus.].

5. R.U. Ayres, Turning point: an end to the growth paradigm. London: Earthscan Publications Ltd (1998).

6. J. Svarc, M. Dabic, Evolution of the knowledge economy: a historical perspective with an application to the case of Europe. Journal of the Knowledge Economy, 8(1), 159-176 (2017).

7. E.S. Shennikova, Knowledge as an object of theoretical analysis. Bulletin of the Institute of Economics of the Russian Academy of Sciences, 4, 428-437 (2009). [in Rus.]. 
8. A. Shahabadi, F. Kimiaei, M.A. Afzali, The evaluation of impacts of knowledge-based economy factors on the improvement of total factor productivity (a comparative study of emerging and G7 economies). Journal of the Knowledge Economy, 9(3), 896-907. DOI: 10.1007/s13132-016-0379 (2018).

9. A.M. Mikhailov, The realization of economic and institutional interests in the process of innovational economy formation in Russia. Economic sciences, 8(105), 39-43 (2013). [in Rus.].

10. R. Bukht, R. Heeks, Defining, conceptualising and measuring the digital economy. International Organisations Research Journal, 13(2), 143-172. DOI: 10.17323/1996-7845-2018-02-07 (2018).

11. A. De Geus, The living company. Harvard Business Review. URL: https://hbr.org/1997/03/the-living-company (1997).

12. P.F. Drucker, Post capitalist society. New York, N.Y.: Harper Business (1993).

13. V.L. Inozemcev, Modern post-industrial society: nature, contradictions, prospects. Moscow: Logos (2000). [in Rus.].

14. N.Yu. Kaufman, E.V. Shirinkina, Features of formation of managerial innovations in the development of human capital. Fundamental Research, 1, 169-172 (2017). [in Rus.].

15. C. Antonelli, Knowledge exhaustibility and Schumpeterian growth. The Journal of Technology Transfer, 43(3), 779-791 (2018).

16. M. Konovalova, O. Kuzmina, A. Mikhailov, S. Salomatina, Entrepreneurship in the system of production factors. Questions of Economics and Law, 4(106), 33-36 (2017). [in Rus.].

17. M. Konovalova, O. Kuzmina, A. Mikhailov, Formation of human capital based on information and knowledge. Economy and Property Management, 1, 57-61 (2018). [in Rus.].

18. E.U. Pronina, A.M. Mikhailov, Economic nature of intellectual capital and its interconnection with human capital assets. Vestnik of Samara State University of Economics, 5, 85-89 (2013). [in Rus.].

19. R. Glauber, D.B. Claro, A systematic mapping study on open information extraction. Expert Systems with Applications, 112, 372-387 (2018).

20. H.E. Daly, Beyond growth: The economics of sustainable development. Boston: Beacon Press (1997).

21. Y. Han, D. Li, Effects of intellectual capital on innovative performance: The role of knowledge-based dynamic capability. Management Decision, 53(1), 40-56 (2015).

22. M. Konovalova, O. Kuzmina, A. Mikhailov, R. Hansevyarov, N. Persteneva, Intellectual capital as a key factor in the economic development of the region. Global Media Journal, 14(27), 39 (2016). [in Rus.].

23. V. Vishnever, R. Khansevyarov, A. Mikhailov, Economic and institutional interests in the global economy. In T. Kliestik (Ed.), Globalization and its socio-economic consequences. 16 International Scientific Conference (Part 3). (pp. 1378-1384), Rajecke Teplice (Slovak Republic): EDIS Zilina University publisher (2016).

24. S. Ansari, A. Roodbari, L.R. Aboosaeidi, H. Nassaji, Intellectual capital as the facilitating infrastructure of knowledge creating and sharing. International Journal of Economics, Commerce and Management, 4(6), 100117 (2016).

25. A.M. Mikhailov, The evolution of production factors interaction under the shifts of technological modes of production. Economic Sciences, 2(135), 19-22 (2016). [in Rus.].

26. S. Kagan, A. Hauerwaas, V. Holz, P. Wedler, Culture in sustainable urban development: Practices and policies for spaces of possibility and institutional innovations. City, Culture and Society, 13, 32-45 (2018).

27. E. Karova, A. Mikhailov, The key transformation aspects of the industrial production mode into the innovational. Vestnik of Samara State University of Economics, 113(3), 54-60 (2014). [in Rus.]. 